Contents

List of Figures $\quad x i$

List of Tables xix

Foreword: Astronomy, Anthropology, and Anthony Aveni

E. C. Krupp $\quad x x i$

Preface $\quad x \times v$

Acknowledgments $\quad x x i x$

\title{
Part I. Introduction
}

I. An Interdisciplinary Approach to Cosmology,

Calendars, and Horizon-Based Astronomy

Susan Milbrath and Anne S. Dowd 3

Part II. Horizon-Based Astronomy

2. Pyramids Marking Time: Anthony F. Aveni's

Contribution to the Study of Astronomical

Alignments in Mesoamerican Architecture

Ivan Šprajc Iq

3. Maya Architectural Hierophanies

Anne S. Dowd 37 
4. Mountain of Sustenance: Site Organization at Dainzú-Macuilxóchitl and Mesoamerican Concepts of Space and Time Ronald K. Faulseit 77

\section{Part III. Cosmological Principles}

5. The North Celestial Pole in Ancient Mesoamerica Clemency Coggins IOI

6. A Seasonal Calendar in the Codex Borgia Susan Milbrath 139

7. Iconography and Metaphorical Expressions Pertaining to Eclipses: A Perspective from Postclassic and Colonial Maya Manuscripts Gabrielle Vail ${ }_{1} 63$

8. The Maya Deluge Myth and Dresden Codex Page 74: Not the End but the Eternal Regeneration of the World

John B. Carlson 197

Part IV. Calendar Records

9. The Ancient Maya Moon: Calendar and Character Flora Simmons Clancy 229

ıo.Pecked Circles and Divining Boards:

Calculating Instruments in Ancient Mesoamerica David A. Freidel and Michelle Rich 249

Ir. The "Las Bocas Mosaic" and Mesoamerican Astro-Calendrics: "Calculator" or Hoax?

Prudence M. Rice 265 
I2. Some Alternative Eclipse Periodicities in Maya Codices

Victoria R. Bricker and Harvey M. Bricker 285

I3. Modeling Indigenous Mesoamerican

Eclipse Theory

John Justeson zoI

Part V. Conclusion

I4. Maya Books and Buildings at Baktun's End

Anthony F. Aveni 353

List of Contributors $\quad 363$

Index $37{ }^{I}$ 
An Interdisciplinary Approach to Cosmology, Calendars, and HorizonBased Astronomy

Susan Milbrath and

This volume highlights the latest research on the role of astronomy in ancient Mesoamerica, an area spanAnne S. Dowd ning Mexico south to Honduras that is of special interest in the field of archaeoastronomy. Our field has come to be known more broadly as cultural astronomy because archaeology, ethnohistory, and ethnography are all important aspects of analysis. Anthony F. Aveni's work has played a seminal role in this interdisciplinary field, and chapters published here cover many themes in his broad-ranging research. Chapters focusing on Mesoamerican horizon-based astronomy in the opening section of this book precede those that investigate the cosmological principles inherent in Mesoamerican religious imagery and rituals related to astronomy. The volume concludes with chapters that analyze Mesoamerican calendar records related to archaeoastronomy and a chapter by Aveni appraising the research compiled in this volume and other new initiatives that promise to be at the forefront of future studies.

We are happy to be riding a wave of heightened interest in Mesoamerican archaeoastronomy, enhanced no doubt by a focus in the popular press on dire predictions for the "end" of the Maya calendar on the winter solstice December 2I, 20I2. For years leading up to this date, people frequently asked about what the Maya said about 2012 and whether there was any validity to the astronomical events invoked. We responded by giving lectures and some even wrote books debunking the

DOI: 10.5876/9781607323792.coor 
view popularized by new age "philosophy," but it does remain intriguing that the Maya may have timed the rollover of the baktun cycle to coincide with the winter solstice. Here we have a chance to show how astronomy and the calendar were indeed closely linked in Maya thought. We can also raise broader issues about Mesoamerican patterns that show the role astronomy played in artistic representations, ceremonies, calendar records, architectural constructions, and urban planning. Since we are incorporating a number of different Mesoamerican civilizations, each with slightly different chronological periods, we refer the reader to table I.I for a comparison of time periods for the four main geographical areas covered in this volume: the Gulf Coast, Oaxaca, the Maya Lowlands, and the Central Mexican Highlands.

The long count calendar of Mesoamerica traces specific astronomical events back to at least A.D. I43, and it is now apparent that the unique Mesoamerican sacred round calendar of 260 days was used to track eclipses and the Venus cycle at this early time at sites like La Mojarra, Mexico. These findings and other cutting-edge research in this volume represent a significant contribution to current scholarship from a variety of disciplines. Interdisciplinary studies are becoming more and more popular, as it has become apparent that making new discoveries often involves going beyond the established parameters of an individual discipline.

This volume incorporates contributions by anthropologists (V. Bricker and H. Bricker, Dowd, Faulseit, Freidel, Justeson, Rice, Rich, Šprajc, and Vail), many of whom were initially trained as archaeologists or cultural anthropologists, but whose work has expanded to incorporate the tools needed to solve questions about the calendar, architectural orientations, and epigraphy. Astronomers (Aveni, Carlson, and Krupp) contributing to this volume have likewise expanded from their chosen field into the realms of archaeology, anthropology, and art historical analysis. Art historians (Clancy, Coggins, and Milbrath) included in this volume have also contributed to breaking down the barriers between the fields of study, employing data from a broad range of disciplines, including astronomy, natural history, and hieroglyphic studies. These chapters underscore the important role astronomy played in the religious and civic life of the people of Mesoamerica, and this volume will also stand as a major contribution to our understanding of Mesoamerican astronomy.

Principles of time and space, central to Mesoamerican cosmology, are embodied in codices, monumental inscriptions, and astronomically oriented architecture. Architecture designed for marking the passage of the sun along the horizon has a long history in Mesoamerica, traced back to Group E-type building complexes (resembling the typesite of Uaxactún, Guatemala) aligned 


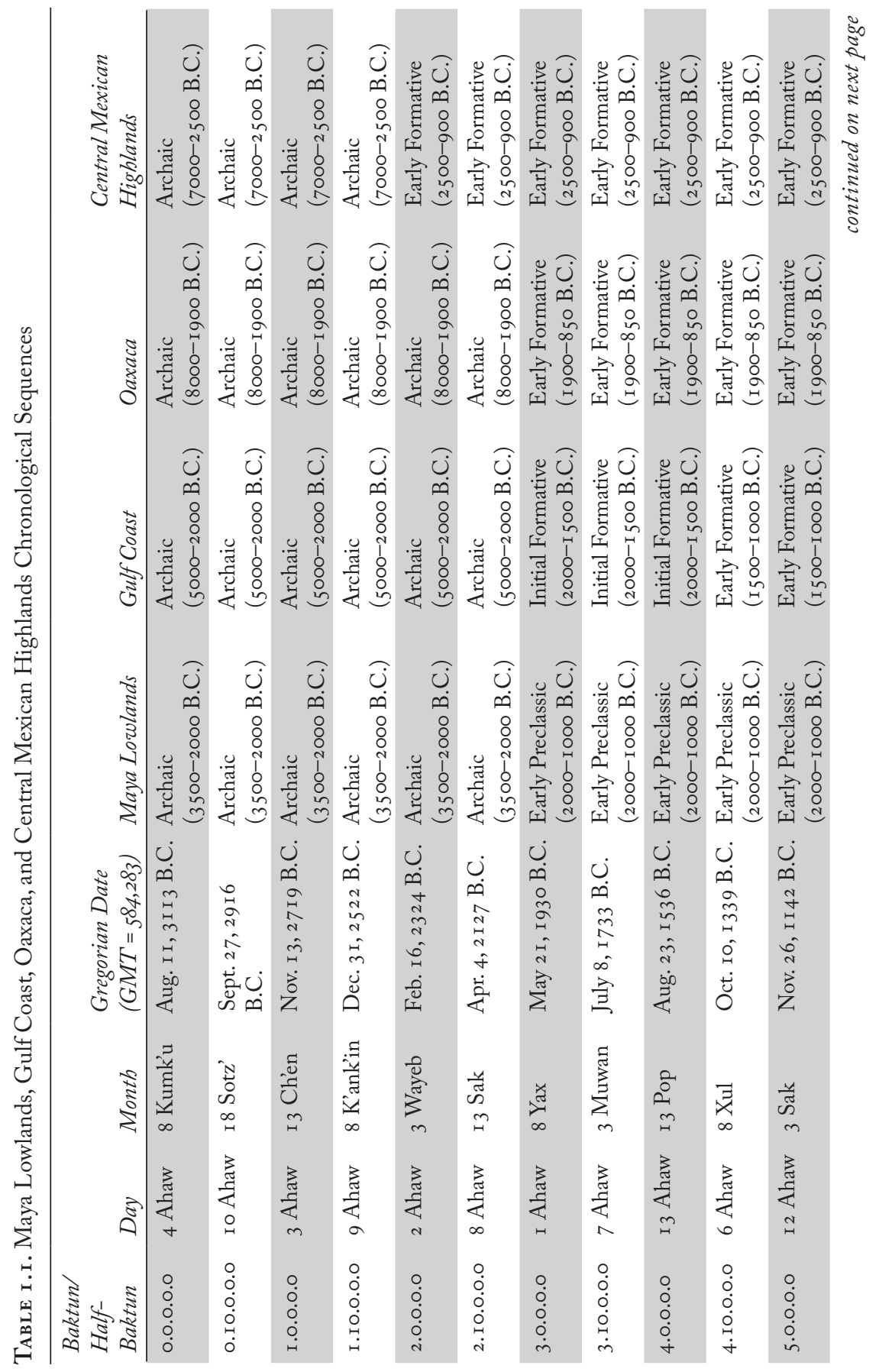




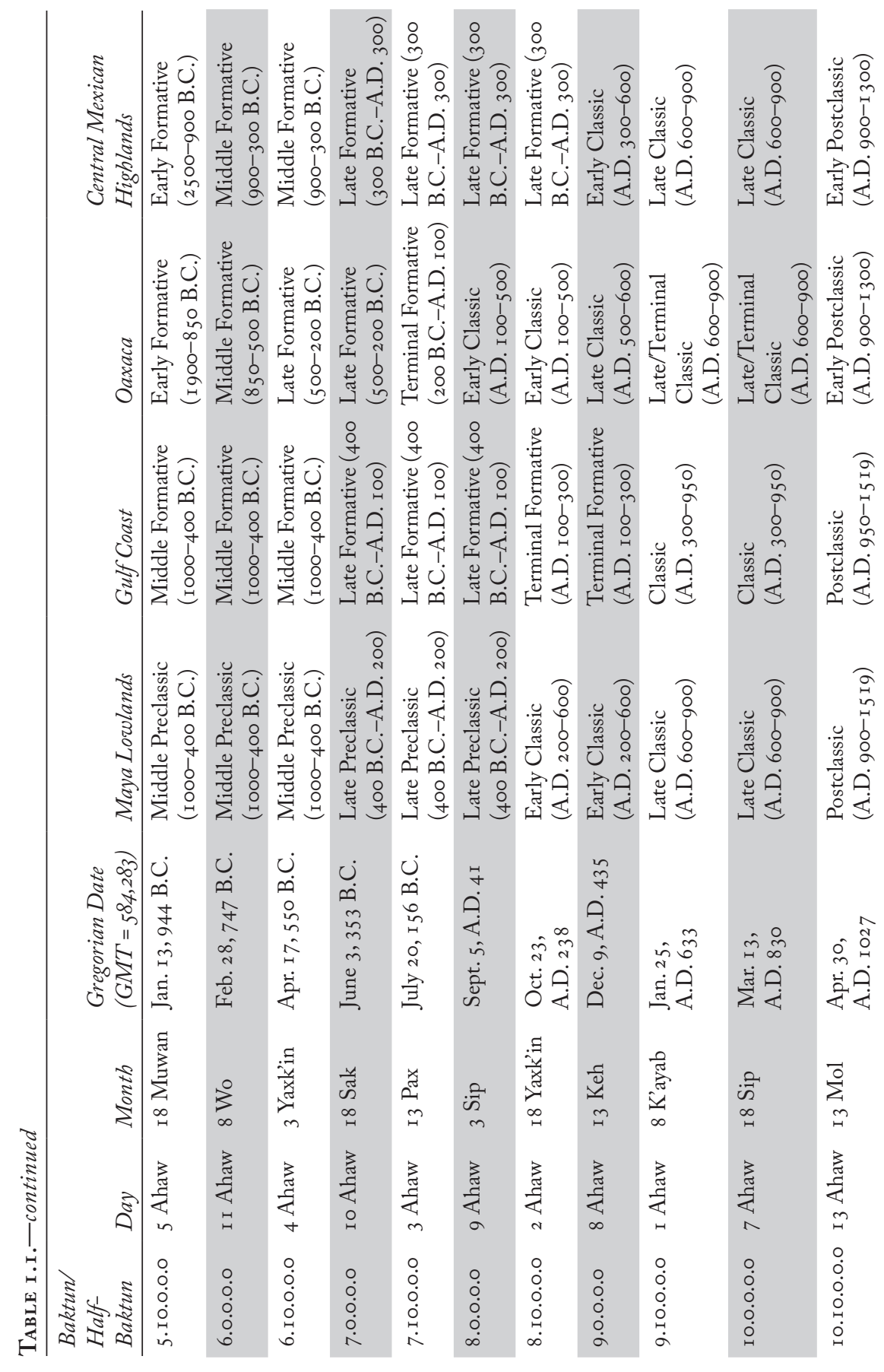




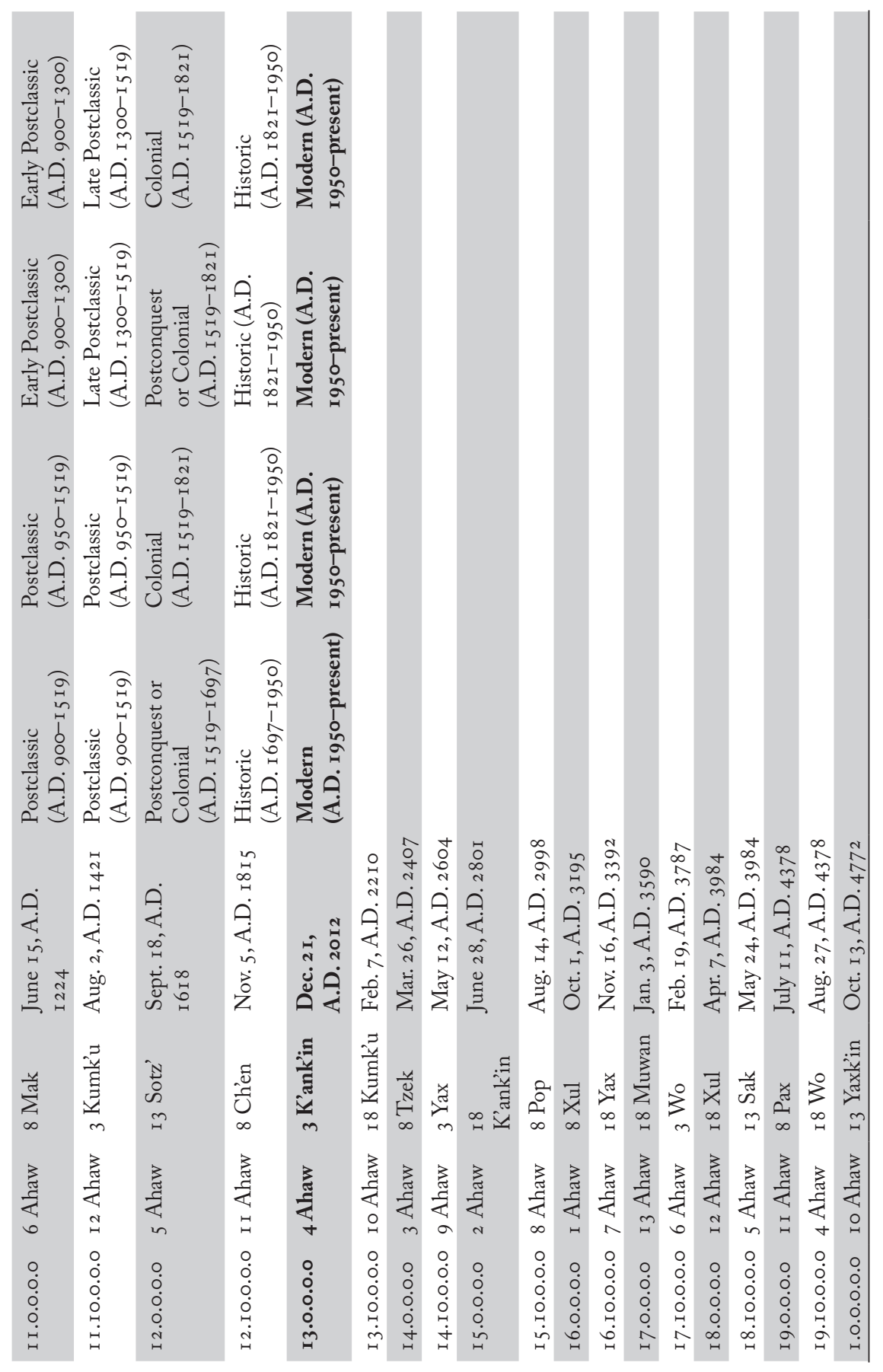


to the equinoxes and the solstices or zenith and nadir passages in the Middle Preclassic period (rooo-400 B.C.). Records of past, present, and future events all incorporate a Mesoamerican calendar based on a repeating cycle of 260 days, employing a set of 20 named days as the basic blocks of time. These $20-$ day periods are also implicit in architectural alignments that reflect an interest in horizon-based astronomy and landscape features, such as sacred mountains. Some alignments anticipate important solar events at $20-$ or $40-$ day intervals, and others mark the position of the sun at 26o-day intervals, dividing the year into two unequal parts.

Like Mesoamerican architecture, calendar records from Mesoamerica incorporate "real-time" observations of events in nature; some are keyed to marking important solar dates. The long count calendar traces specific astronomical events back to at least A.D. I43, and it is now apparent that the unique Mesoamerican sacred round calendar of 260 days was used to track eclipses and the Venus cycle in Terminal Formative (A.D. 100-300) epi-Olmec texts (see Justeson, chapter $\mathrm{I} 3$, this volume). Other records use repeating cycles of time to project back to mythical events in the distant past or to events far in the future.

In the chapters that follow, the integration of time and space in Mesoamerica is explored through study of the calendrical structure, horizon-based astronomy, and recorded observations of natural cycles, especially those featuring astronomical events. A more detailed discussion of the chapters will help frame the contributions in this volume. Following this introduction, in the second section, "Horizon-Based Astronomy," authors treat urban planning principles whereby interbuilding alignments and landscape characteristics were used to observe or emphasize movements of celestial bodies. Chapter 2, by Ivan Šprajc and entitled "Pyramids Marking Time: Anthony F. Aveni's Contribution to the Study of Astronomical Alignments in Mesoamerican Architecture," emphasizes Aveni's pioneering role in archaeoastronomy and establishes the book's theme. A huge corpus of alignment data first collected by Aveni and later augmented by Šprajc is analyzed in light of recent advances in the understanding of the role of astronomy and cosmology in Mesoamerican architectural and urban planning. Šprajc employs statistical analysis to discover the patterns of orientation most prominent in Mesoamerican civic and ceremonial architecture, helping define the primarily solar dates of greatest interest in the alignments evident in architectural orientations throughout Mesoamerica.

The third chapter, "Maya Architectural Hierophanies," by Anne S. Dowd, explores the role of specific orientations in creating dramatic displays of light and shadow on Maya buildings. A famous example is that of El Castillo pyramid at Chichén Itzá, where the sun illuminates a serpent balustrade on March 
20, the spring equinox, and again on September 22, the fall equinox. The range of events displayed in the context of architectural space, such as solstice sunrise and sunset or zenith and nadir passages in Group E-type complexes, is also discussed. This chapter also emphasizes the role of celebrations and observations of solar movements in Maya urban planning and state formation.

The fourth chapter, "Mountain of Sustenance: Site Organization at DainzúMacuilxóchitl and Mesoamerican Concepts of Space and Time" by Ronald K. Faulseit, offers evidence of the relationship between landscape features, solar observations, and the seasonal cycle, as expressed in Oaxaca's Terminal Formative (200 B.C.-A.D. I0o). Cerro Danush is a prominent solitary mountain at the northern end of Dainzú-Macuilxóchitl in Oaxaca. In Oaxaca's Late/ Terminal Classic period (A.D. 600-900), its peak was transformed into a temple-patio-altar complex that archaeological evidence suggests was associated with Cociyo, the Zapotec god of lightning, rain, and sky. At the other end of the site, the complex is oriented southwest toward the base of Cerro Dainzú, where carved stone depictions of ball players and jaguar motifs connect it to warfare, death, and the underworld. Faulseit discusses how this contrast of earth and sky domains forms an axis mundi that unites the site's spatial organization with the ritual calendar and the motion of the sun on the horizon.

Part III in this volume, "Cosmological Principles," focuses on the role of astronomy in Mesoamerican religious iconography, seasonal festivals, and cosmology of world creation and destruction. In chapter 5, "The North Celestial Pole in Ancient Mesoamerica," Clemency Coggins traces the evolving and adapting calendric role of the Celestial Pole and its personification in Middle and Late Preclassic (1000-400 B.C. and 400 B.C.-A.D. 200) Mesoamerica. As the focus of the layout of many ancient Mesoamerican sites, the significance of the direction north changed through time in some instances, while remaining constant in others, as seen in a persistent association between the concept of north and the face of "God C." The controversial topic of the Maya understanding of "north" is considered in a long-term context, and this chapter also explores the relationship between the concept of north and Maya images of 7 -Macaw, the false sun in the Popol Vuh.

The 20-day periods expressed in the 365 -day festival calendar are linked with fundamental religious principles in the iconography and cosmology of Postclassic Central Mexico in chapter 6, entitled "A Seasonal Calendar in the Codex Borgia" by Susan Milbrath (see also Milbrath 1999, 2013). This chapter features an eighteen-page narrative in the Codex Borgia with an embedded festival calendar that represents changing seasonal images over the course of a year. Using only calendar dates and cartoon-like images, the Codex Borgia 
expresses complex principles that involve "real-time" astronomical events linked with religious imagery, a pattern first explored by Aveni (1999). Rainyseason images include bees, hummingbirds, an abundance of maize and flowers, and a flowered temple that houses the rainy-season Sun God on the summer solstice and fall equinox. In contrast, images of the winter solstice and spring equinox show fire-serpent temples representing the dry season, and generally the dry season is linked with symbols related to war and fire gods. Venus gods also undergo seasonal transformation, helping to explain the multiple manifestations of Venus imagery in the narrative.

The seventh chapter, Gabrielle Vail's "Iconography and Metaphorical Expressions Pertaining to Eclipses: A Perspective from Postclassic and Colonial Maya Manuscripts," explores recent research suggesting that the Maya scribes who drafted the Postclassic (A.D. 900-1519) Venus table mapped events from primordial time onto historical dates associated with observations of the planet. The table highlights the Morning Star period of Venus, represented by three separate figures per page: (I) a presiding deity, (2) a warrior corresponding to heliacal rise, and (3) the warrior's victim. Although presiding deities and victims are Maya in origin, most of the warriors derive from "foreign" sources, including Central Mexico. This chapter examines how the authors of the table adapted ideas and stories from distant places to construct a narrative highlighting events and figures from mythic time.

John B. Carlson's contribution, "The Maya Deluge Myth and Dresden Codex Page 74: Not the End but the Eternal Regeneration of the World," (chapter 8), analyzes imagery from a Postclassic Maya codex to lend a new understanding of what had previously been interpreted as a cataclysmic flood event. Instead, Carlson draws upon annual seasonal patterns to suggest simply that the water representation on page 74 of the Dresden Codex indicates the seasonal rains. Rather than world destruction, world renewal is the theme expressed. Carlson's discussion of floods may be related to some of the points the Brickers have raised in chapter I2, which also refers to torrential rain or flood imagery, from the Dresden Codex.

Part IV, "Calendar Records," begins with chapter 9, entitled "The Ancient Maya Moon: Calendar and Character," in which art historian Flora Simmons Clancy treats the role of astronomy in calendar inscriptions and other forms of recording calendar intervals. She discusses Classic period (A.D. 200-900) Maya lunar data known as the Lunar Series. These texts found in Maya in long count inscriptions consist of six to ten glyphs embedded in the long Initial Series date in monumental art. Clancy begins with an analysis of the Lunar Series by looking at monuments bearing the same Initial Series date 
but citing different lunar data, and explores the implications for counting by days versus counting by nights. Clancy then examines lunar inscriptions relating to concepts of narrative and iconography in Classic Maya art.

In chapter Io, "Pecked Circles and Divining Boards: Calculating Instruments in Ancient Mesoamerica," David A. Freidel and Michelle Rich provide a bridge between the calendar reckonings of the Maya and those of Central Mexico. Aveni has long proposed that the lowland Maya adopted important notions of calendar calculation from Teotihuacán. Aveni's (2005) arguments are based significantly on the correspondence of pecked circles at Teotihuacán and at Uaxactún. Discussing pecked devices along the south side of the Pyramid of the Sun, the authors propose that these may also have been used for divinatory purposes. They link these devices to Classic period Maya representations of tablets and mirrors, suggesting they are calculating devices that are also used for divination and writing.

An early calculating device for the calendar is investigated in chapter II, entitled "The 'Las Bocas Mosaic' and Mesoamerican Astro-Calendrics: 'Calculator' or Hoax?" Here Prudence M. Rice studies the calendar intervals expressing an interest in the Venus cycle and other astronomical periodicities that are purportedly incorporated in a unique mirror, attributed to the Middle Formative period (900-300 B.C.) site of Las Bocas in Central Mexico. This chapter explores the calendrical patterns expressed in its mosaic pieces, arranged in three triptych-like panels; the left and center hold ${ }_{2} 28$ tesserae in groupings of four, but the right panel lacks such regular arrangement. Originally thought to have some possible lunar tallying function, this plaque can be used to compute the days of the Mesoamerican 260-day, 365-day, and Venus calendars as well as other significant calendrical intervals. The plaque is either an elaborate hoax or a sophisticated calculation device for calendrical computations. Rice concludes that its uniqueness by no means discounts the possibility that it is authentic, for the accidents of preservation in an archaeological context have resulted in a number of unique objects.

In chapter I2, entitled "Some Alternative Eclipse Periodicities in Maya Codices," Victoria R. Bricker and Harvey M. Bricker explore a table of possible eclipse cycles based on multiples of the lunar synodic month. Of the twenty-five eclipse periodicities listed, only two appear in the Precolumbian Maya codices. Several tables and almanacs in the surviving codices, however, contain evidence of alternative and apparently culturally more salient eclipse periodicities that commensurate more directly with the 260-day sacred calendar of the Maya (tzolkin), even though they are not close to integral multiples of the lunar synodic month. 
John Justeson explores the relationship of eclipse occurrence to the ancient Mesoamerican calendar in chapter I3, titled "Modeling Indigenous Mesoamerican Eclipse Theory." Justeson traces calendar dates recording eclipses as far back as A.D. I43 in the Veracruz Terminal Formative (A.D. Ioo-300). The study builds on the well-known correlation of the 26o-day cycle with eclipse timing, due to the near equivalence of the span of two divinatory-calendar cycles (520 days) with the time to pass from a node of the eclipse cycle to the third subsequent node (519.93 days). Mesoamericans are not imagined to have had an explicit concept of eclipse nodes; however, by exploring temporal patterns in the timing of lunar eclipses visible in Mesoamerica, this chapter presents a Mesoamerican-type model for eclipse occurrence based on cyclic recurrences in the divinatory calendar, along with a possible reflection in the practices of Colonial Zapotec calendar specialists.

In part V, "Conclusions," Anthony F. Aveni appropriately gets the "last word" in the final chapter of the volume honoring his legacy. In chapter I4, "Maya Books and Buildings at Baktun's End," he synthesizes the major contributions of this volume and also notes other new discoveries, such as the Xultun texts recording Classic Maya tables for tracking the cycles of Venus, Mars, and the Moon (Saturno et al. 20I2). Aveni's chapter sets the stage for future endeavors in archaeoastronomy by highlighting major advances and new directions in research.

Themes that reappear in several of the chapter include the concept of a city as an axis mundi, bringing the cosmos into a coherent vertical hierarchy. Other important themes include the city and its plan as a calendar that charts horizontal angles related to the rising and setting of astronomical bodies, number and temporal cycle groupings and intercalation, seasonal correlates of horizontal divisions in the year and spatial divisions in the community or landscape. Also featured is the use of topography in addition to the built environment for astronomical observation or a geomantic perspective, foundations of rulership based upon specialized esoteric knowledge, and other aspects of cultural astronomy or archaeoastronomy.

This volume makes a significant contribution to the understanding of ideas related to symbolism, creation mythology, and spatial organization. It reflects theoretical perspectives ranging from George Kubler's (1977) reliance upon principles of cultural disjunction to Clifford Geertz's (1980) rise of the theater state though performative ritual. Micea Eliade (1958, 1959) is cited by a number of the authors on the topics of hierophanies, axis mundi, and sacred acts. Although traditionally in Mesoamerica theoretical principles have been only loosely connected to data, this volume gives readers a somewhat stronger 
set of relationships between theory and data. For example, in chapter 3 Dowd proposes that a series of tropic relations exist between the part (e.g., a building, or city plan) and a whole (e.g., a cosmogram), drawing upon Terrence Turner's (I99I) pivotal efforts in the areas of interactivist or constructivist theory. Faulseit's idea in chapter 4 that a Zapotec city was essentially a world map or a cosmogram can be applied more broadly in our understanding of Mesoamerican urban planning. The complementary opposites of sky-earth, up-down, rainy-dry seasons also leads us back to theoretical principles established by a long line of anthropologists and scholars of religious studies.

By using the calendar and knowledge of mathematics, astronomy, written language, and other modes of cultural and artistic expression, ancient Mesoamerican people were developing prestige technologies. In this sense, the authors of this volume have all described facets of these technologies and are contributing to an anthropological study of technology (Lemonnier I986, 1992; Pfaffenberger 1988, 1992). This approach, known as the anthropology of technology, explores the ways in which technology is embedded in social, economic, and religious life. Manipulating technology was a means of acquiring or differentiating status that created and maintained social divisions between elites and commoners in Mesoamerican societies. Technology in this theoretical perspective is part of a larger system, one that interpenetrates other cultural subsystems, such as kinship, religion, agriculture, and education. In order to balance the limitations of this form of systems theory, we should consider processes of individual agency and more unique historical trajectories that are accessible when and where written records exist (Dowd I998a, I998b).

Brian Hayden (1998) has related prestige technologies to the emergence of social complexity among sedentary hunter-gatherer populations, but understanding the emergence of Mesoamerican primary and secondary states may also be tackled with an anthropology of technology, with special attention to the development of technologies that reinforced social status for the purpose of labor acquisition and control. In addition to hieroglyphic writing, monumental art and architecture, and mathematical and astronomical data incorporated in the calendar, Mesoamerican cultures perfected irrigation technologies and water control systems to support maize agriculture, and trading and lithic technologies surrounding semiprecious jade, and they also integrated performance into religious rituals from a relatively early time period. This suite of elaborate technologies helped attract labor and economically valuable allies to foster community growth. Seen from the standpoint of an anthropology of technology, with a focus upon prestige technologies as catalysts of social change in emerging chiefdoms and states (Redmond and Spencer 20I2, Spencer 2010), 
Mesoamerican cultural groups created multilayered symbolic representations of their world for the purpose of persuading people to follow their economic, religious, and political points of view through ritual performances uniting communities around common goals and programs, such as the institution of kingship. The authors bring together the kind of information that allows us to see the integration of architecture, the calendar, and social process, all of which form the building blocks for advancing theoretical perspectives.

On a more pragmatic level, our volume could be useful for future analysis of landscape patterns. Although landscape archaeology has not often been explicitly related to the study of Mesoamerican archaeoastronomy in the past, the emergence of Geographic Information Systems (GIS) and the use of Global Positioning System (GPS) coordinates for creating more accurate digital map layers has the potential to transform archaeoastronomy. Three-dimensional mapping using Light and RADAR (LiDAR) or digital modeling that includes astronomical data is still in its infancy, but it is a worthwhile goal to model terrestrial spatial data and celestial spatial data simultaneously so that temporal changes can be diagrammed. John Fillwalk (personal communication, 2013) has shown how sophisticated computer graphics can be merged with archaeological, topographic, and astronomical data to produce four-dimensional site models designed to show how the people who built an ancient site used architecture and land and skyscape in modeling their universe. These kinds of GIS or remote sensing applications or computer simulations can be used in archaeoastronomy, producing results that will permit more precise models of architecture, horizon lines, and relationships among rising and setting astronomical bodies. Many of the chapters in this book could potentially contribute to the data employed in GIS or remote sensing techniques designed for the field of archaeoastronomy. Programs such as ArcGIS or ArcINFO now facilitate what were only theoretical possibilities a few years ago.

The contributors to this volume have provided evidence for the concept of a city as a calendar. The overall consensus appears to be that far from a single structure within a community functioning as an observatory, the built environment generally held such a role. Each polity likely created a unique set of topographic patterns that were integrated with natural astronomical cycles so that this astronomical-architectural interaction could be seen as a multidimensional calendar. Increasing evidence for interpreting seasonal and agricultural symbolism in the context of urban planning and religious ritual suggests that each time Mesoamerican architects and builders designed a new city, special principles of organization were applied in planning (Ashmore 199I). In this way, the Mesoamerican cultural groups we have studied in this 
volume merged technology with social and economic life. We are fortunate to have many new themes available for study in the very near future, building upon the thorough research offered by the authors of this volume.

We have only touched upon theoretical constructs guiding the research presented here on calendars, cosmology and astronomy. Still, connecting theory, method, and data is a worthwhile goal. Having the advantage of written records-in the form of inscribed monuments, codices (or foldingscreen books), ethnohistoric accounts dating to just after the conquest, and ethnographies from our era-provides an enormous amount of emic (insider), as opposed to etic (outsider), information. Given that we have access to the cultural perspective of the groups we are studying, multiple lines of evidence can be used to support many of the authors' conclusions.

\section{REFERENCES}

Ashmore, Wendy. 1991. "Site-Planning Principles and Concepts of Directionality among the Ancient Maya." Latin American Antiquity 2 (3): 199-226. http://dx.doi .org/10.2307/972169.

Aveni, Anthony F. 1999. "Astronomy in the Mexican Codex Borgia." Archaeoastronomy, no. 24 (supplement to Journal for the History of Astronomy 30):SI-20.

Aveni, Anthony F. 2005. "Observations on the Pecked Designs and Other Figures Carved on the South Platform of the Pyramid of the Sun at Teotihuacan." Journal for the History of Astronomy 36:3I-47.

Dowd, Anne S. r998a. "Biface Standardization Accompanying Organized Chert Quarrying Efforts: An Argument for Intensifying Lithic Production." In Craft Specialization: Operational Sequences and Beyond. Papers from the European Association of Archaeologists Third Annual Meeting at Ravenna 1997, vol. 4, edited by S. Milliken and M. Vidale, 69-75. BAR International Series 720. Oxford: British Archaeological Reports.

Dowd, Anne S. 1998b. "Operationalizing an Anthropology of Technology: Lithic Procurement and Tool Production among North American Hunter-Gatherers." In Lithic Technology: From Raw Material Procurement to Tool Production. Proceedings of the Workshop No. I2 of the XIII International Congress of Prehistoric and Protohistoric Sciences, edited by S. Milliken and M. Peresani, Io9-Iz. Forlí, Italy: M.A.C.

Eliade, Mircea. 1958. Patterns in Comparative Religion. New York: Sheed and Ward. Eliade, Mircea. 1959. The Sacred and the Profane: The Nature of Religion. Translated by W. R. Trask. New York: Harcourt. 
Geertz, Clifford. 1980. Negara: The Theatre State in Nineteenth-Century Bali. Princeton, NJ: Princeton University Press.

Hayden, Brian. 1998. "Practical and Prestige Technologies: The Evolution of Material Systems." Journal of Archaeological Method and Theory 5 (I): I-55. http://dx.doi.org /10.1007/BFo2428415.

Kubler, George. 1977. "Renascence and Disjunction in the Art of Mesoamerican Antiquity." In Ornament, edited by Stephan Kieran, 3I-4I. Via, no. 3. Philadelphia: Graduate School of Fine Arts, University of Pennsylvania.

Lemonnier, Pierre. 1986. “The Study of Material Culture Today: Toward an Anthropology of Technical Systems." Journal of Anthropological Archaeology 5 (2): I47-86. http://dx.doi.org/Io.Ior6/o278-4165(86)9oor2-7.

Lemonnier, Pierre. 1992. Elements for an Anthropology of Technology. Anthropological Papers, no. 88. Ann Arbor: Museum of Anthropology, University of Michigan.

Milbrath, Susan. 1999. Star Gods of the Maya: Astronomy in Art, Folklore, and Calendars. Austin: University of Texas Press.

Milbrath, Susan. 2013. Heaven and Earth in Ancient Mexico: Astronomy and Seasonal Cycles in the Codex Borgia. Austin: University of Texas Press.

Pfaffenberger, Bryan. I988. "Fetished Objects and Humanized Nature: Towards an Anthropology of Technology." Man 23 (2): 236-52. http://dx.doi.org/Io.2307 /2802804.

Pfaffenberger, Bryan. 1992. "Social Anthropology of Technology." Annual Review of Anthropology 2I (I): 49I-5I6. http://dx.doi.org/Io.II46/annurev.an.2I.IooI92.002423.

Redmond, Elsa M., and Charles S. Spencer. 2or2. "Chiefdoms at the Threshold: The Competitive Origins of the Primary State." Journal of Anthropological Archaeology 3I (I): 22-37. http://dx.doi.org/ro.IoI6/j.jaa.20II.09.002.

Saturno, William A., David Stuart, Anthony F. Aveni, and Franco Rossi. 2012.

"Ancient Maya Astronomical Tables from Xultun, Guatemala." Science 336 (6082): 714-I7. http://dx.doi.org/Io.II26/science.I22I444.

Spencer, Charles S. 2oro. "Territorial Expansion and Primary State Formation.” Proceedings of the National Academy of Sciences of the United States of America Io7 (I6): 7II9-26. http://dx.doi.org/Io.Io73/pnas.Ioo2470107.

Turner, Terence S. 199r. “We Are Parrots,' 'Twins Are Birds': Play of Tropes as Operational Structure." In Beyond Metaphor: The Theory of Tropes in Anthropology, edited by J. M. Fernandez, I2I-58. Stanford, CA: Stanford University Press. 